\title{
A new method for handoff target network selection
}

\author{
Jyoti Madaan, Sunanda Gupta, Pratima Manihas \\ Manav Rachna International Institute of Research and Studies, Faridabad Haryana, New Delhi
}

\begin{tabular}{l} 
Article Info \\
\hline Article history: \\
Received Nov 11, 2018 \\
Revised Jan 20, 2019 \\
Accepted Feb 5, 2019 \\
\hline Keywords: \\
Always best connected services \\
(ABC) \\
Handoff target network \\
selection and execution module \\
(HTSM) \\
Quality of service (QoS) \\
Universal mobile \\
telecommunication service \\
(UMTS) \\
Wireless local area network \\
(WLAN)
\end{tabular}

\begin{abstract}
In wireless communications of fourth generation the expectation to assimilate a hypothetically numerous heterogeneous wireless technologies are happened under consideration of a novel step toward worldwide smooth access. The advancement in wireless networks increases the challenges of mobility management as well the challenges of merging a various number of wireless networks. Out of those the main challenge for smooth movement is the accessibility of consistent vertical (intersystem) and horizontal (intra-system) handoff processes. So to improve the quality of service and to provide always best connected services all the time, the handoff decision algorithm must select an optimum target network from the available candidate networks. The purpose of this paper is to provide a mechanism for selecting an optimum target network from the available networks. This method is devised for maximizing the user satisfaction level, by selecting the "best" network as the handover target network among multiple candidate networks.
\end{abstract}

Copyright $(5) 2019$ Institute of Advanced Engineering and Science. All rights reserved.

\section{Corresponding Author:}

Jyoti Madaan,

Manav Rachna International Institute of research and studies, Faridabad Haryana, 121003 New Delhi.

Email: Jyotiverma.fet@mriu.edu.in

\section{INTRODUCTION}

Nowadays, mobile communication has heterogeneous wireless networks offering variable coverage and QoS. Heterogeneous wireless networks are one of the most important structures that are needed for deployment of wireless technologies such as fourth generation $(4 \mathrm{G})$ mobile systems. The heterogeneous wireless network is a mixture of various access technology to allow the user to have seamless mobility and best quality of service at all time such as high coverage of cellular networks and high bandwidth of Wireless Local Area Network (WLAN) [1-2]. But to allow seamless mobility and always best connected services to mobile user, there is a need to develop an algorithm to select an optimum target network from the available network.

Some solutions to handover target selection algorithms were discussed by Zhu and McNair [3-5]. The authors have proposed a Cost function based algorithm to select an optimum target network. The total cost is the sum of the cost of each QoS parameter, including the bandwidth, battery power and delay. It calculates a cost for all the candidate networks based on static and dynamic parameters. The network with the minimum cost is selected as the handover target network. This method has increased the percentage of user satisfied requests and reduced the call blocking probability. However, the authors did not discuss how the weights for the QoS factors were assigned and normalized. 


\section{OVERVIEW OF HANDOFF TARGET NETWORK SELECTION AND EXECUTION MODULE (HTSM)}

HTSM algorithm selects an optimum target network from the available candidate networks to provide Always Best Connected Services (ABC) to users. It consists of two units-Weight Estimation unit and Handoff Factor Estimation unit. Figure 1 shows the block diagram of HTSM. The HTSM module takes the input from Weight Estimation unit and Handoff Factor Estimation unit and generates an output depending upon the score attained by a candidate networks.

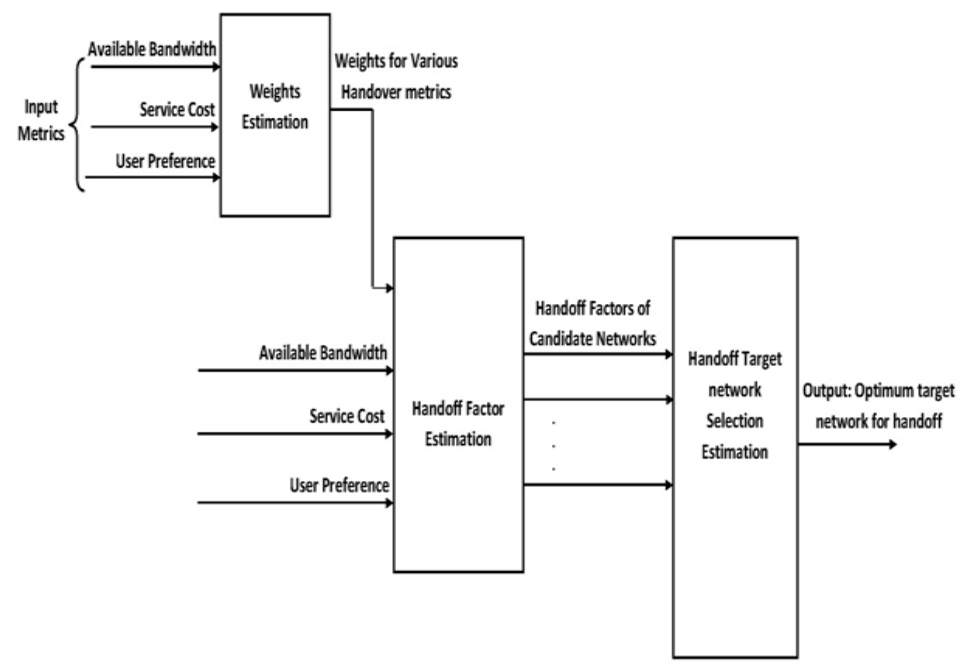

Figure 1. Handoff Target Network Selection and Execution Module (HTSM)

\subsection{Weights Estimation Unit}

The Weights Estimation unit takes available bandwidth, service cost and user preference as input decision parameters, and generates weight factors for these handover decision parameters as outputs. Weight factors of handover decision parameters show the importance levels for the network parameters. Weight Estimation unit calculates weight factors of decision parameters (available bandwidth, monetary cost, and user preference) using a method described below. The method assumes that the weight factors of the network parameters, available bandwidth, monetary cost, and user preference, are $\mathrm{W}_{\mathrm{BW}}, \mathrm{W}_{\mathrm{CO}}, \mathrm{W}_{\mathrm{UP}}$, respectively. The values of these weights are fraction and the summation of all weights can be up to one. Where $\mathrm{W}_{\mathrm{BW}}+\mathrm{W}_{\mathrm{CO}}+\mathrm{W}_{\mathrm{UP}}=1$. Since each network parameter has a different unit, it is necessary to normalize them. The normalized value of input parameters (Bandwidth, Cost, and User preference) can be calculated as (1-3) [6-8]:

$$
\begin{aligned}
& \mathrm{N}\left(\mathrm{BW}_{1}\right)=\frac{\mathrm{BW}_{1}-\mathrm{BW}_{\text {min }}}{\mathrm{BW}_{\text {max }}-\mathrm{BW}_{\text {min }}} \\
& \mathrm{N}\left(\mathrm{CO}_{1}\right)=\frac{\mathrm{CO}_{1}-\mathrm{CO}_{\text {min }}}{\mathrm{CO}_{\text {max }}-\mathrm{CO}_{\text {min }}} \\
& \mathrm{N}\left(\mathrm{UP}_{1}\right)=\frac{\mathrm{UP}_{1}-\mathrm{UP}_{\text {min }}}{\mathrm{UP}_{\text {max }}-\mathrm{UP}_{\text {min }}}
\end{aligned}
$$

Where $\mathrm{BW}_{\max }$ and $\mathrm{BW}_{\min }$ are the maximum and minimum bandwidth offered by network 1 . $\mathrm{C}_{\max }$ and $\mathrm{C}_{\min }$ are the maximum and minimum charges of a service. The user preference (UP) range is from 0 to 10. User preference is high, when a user prefers to select WLAN, and it is low if a user prefers to stay in UMTS. For T candidate networks Mean and Standard Deviation of bandwidth, cost, and user preference can be calculated as $(4-9)[9,11]$ :

$$
\mathrm{m}_{\mathrm{BW}}=\frac{1}{\mathrm{~T}} \sum_{\mathrm{t}=1}^{\mathrm{T}} \mathrm{N}\left(\mathrm{BW}_{\mathrm{t}}\right)
$$




$$
\begin{aligned}
& \mathrm{m}_{\mathrm{CO}}=\frac{1}{\mathrm{~T}} \sum_{\mathrm{t}=1}^{\mathrm{T}} \mathrm{N}\left(\mathrm{CO}_{\mathrm{t}}\right) \\
& \mathrm{m}_{\mathrm{UP}}=\frac{1}{\mathrm{~T}} \sum_{\mathrm{t}=1}^{\mathrm{T}} \mathrm{N}\left(\mathrm{UP}_{\mathrm{t}}\right) \\
& \left(\sigma_{\mathrm{BW}}\right)=\sqrt{\frac{1}{\mathrm{~T}-1}} \sum_{\mathrm{t}=1}^{\mathrm{T}}\left(\mathrm{T}\left(\mathrm{BW}_{\mathrm{t}}\right)-\mathrm{m}_{\mathrm{BW}}\right) \\
& \left(\sigma_{\mathrm{co}}\right)=\sqrt{\frac{1}{\mathrm{~T}-1}} \sum_{\mathrm{t}=1}^{\mathrm{T}}\left(\mathrm{T}\left(\mathrm{CO}_{\mathrm{t}}\right)-\mathrm{m}_{\mathrm{co}}\right) \\
& \left(\sigma_{\mathrm{UP}}\right)=\sqrt{\frac{1}{\mathrm{~T}-1}} \sum_{\mathrm{t}=1}^{\mathrm{T}}\left(\mathrm{T}\left(\mathrm{UP}_{\mathrm{t}}\right)-\mathrm{m}_{\mathrm{UP}}\right)
\end{aligned}
$$

In fact, the smaller mean is, the more important the factor is. The larger the standard deviation is, the larger the weight should be assigned. It leads to adjust the weights dynamically by (10-12)

$$
\begin{aligned}
& \phi_{\mathrm{BW}}=\exp \left(-\mathrm{m}_{\mathrm{BW}}+\sigma_{\mathrm{BW}}\right) \\
& \phi_{\mathrm{CO}}=\exp \left(-\mathrm{m}_{\mathrm{CO}}+\sigma_{\mathrm{CO}}\right) \\
& \phi_{\mathrm{UP}}=\exp \left(-\mathrm{m}_{\mathrm{UP}}+\sigma_{\mathrm{UP}}\right)
\end{aligned}
$$

Letting $\phi=\phi_{\mathrm{BW}}+\phi_{\mathrm{CO}}+\phi_{\mathrm{UP}}$, the dynamic weights are defined as (13-15)

Dynamic weight for Bandwidth $\left(\mathrm{W}_{\mathrm{BW}}\right)=\frac{\phi_{\mathrm{BW}}}{\phi}$

Dynamic weight for Cost $\left(\mathrm{W}_{\mathrm{CO}}\right)=\frac{\phi_{\mathrm{CO}}}{\phi}$

Dynamic weight for User preference $\left(\mathrm{W}_{\mathrm{UP}}\right)=\frac{\phi_{\mathrm{UP}}}{\phi}$

where $\mathrm{W}_{\mathrm{BW}}, \mathrm{W}_{\mathrm{CO}}$, and $\mathrm{W}_{\mathrm{UP}}$ are the weight factors to represent the importance of each metric to the user. Through equation 13 to 15 , the mobile node is able to assign weights to the network parameters dynamically.

\subsection{Hand off Factor Estimation}

The Handoff Factor (HF), which provides a measurement of the cost of a certain network can be defined as an improvement gained by the user after switching to a new network regarding to the running services. The handoff factor calculation algorithm evaluates the cost of candidate networks by using a cost function for making a handoff. It takes various network parameters and their weights as inputs and generates handoff factors for all candidate networks. The network with the highest handoff factor is selected as an optimum target network. The Handoff Factor (HF) of a certain network 1, is calculated using the following function (16) [10, 7]:

$$
\begin{aligned}
& \mathrm{HF}_{1}=\frac{\mathrm{W}_{\mathrm{BW}}\left(\mathrm{BW}_{1}\right)}{\max \left(\left(\mathrm{BW}_{1}\right), \ldots \ldots . .\left(\mathrm{BW}_{\mathrm{T}}\right)\right)}+\frac{\mathrm{W}_{\mathrm{co}}\left(1 / \mathrm{CO}_{1}\right)}{\max \left(\left(\frac{1}{\mathrm{CO}_{1}}\right), \ldots \ldots\left(\frac{1}{\mathrm{CO}_{\mathrm{T}}}\right)\right)} \\
& +\frac{\mathrm{W}_{\mathrm{UP}}\left(\mathrm{UP}_{1}\right)}{\max \left(\left(\mathrm{UP}_{1}\right), \ldots \ldots . .\left(\mathrm{UP}_{\mathrm{T}}\right)\right)}
\end{aligned}
$$


Where $\mathrm{BW}_{1}, \mathrm{CO}_{1}, \mathrm{UP}_{1}$ stands for available bandwidth (in Mbps), monetary cost per minute (in cents), and user preference (on a scale of 1 to 10 , from very low to very high), and $\mathrm{W}_{\mathrm{BW}}, \mathrm{W}_{\mathrm{CO}}$ and $\mathrm{W}_{\mathrm{PO}}$ are their weights obtained from the weight estimation algorithm. Lastly, the network with a Handoff Factor (HF) of $\max \left(\mathrm{HF}_{1} ;:: ; \mathrm{HF}_{\mathrm{T}}\right)$ is selected as the handover target. Where $\mathrm{T}$ is the total number of candidate networks.

\section{METHODOLOGY}

The Handoff Target Network Selection \& Execution Module (HTSM) is used to select the best target network from the available networks. In Target network selection process all the candidate networks are analyzed in terms of bandwidth, cost, and user preference. Figure 2 shows the overall workflow of HTSM algorithm. In this, first of all weights are calculated to input decision parameters. After that, the network is analyzed based on Handoff Factor. The Handoff Factor is a function of available bandwidth (BW), usage cost of the network (CO), and user preference (UP). The Handoff Factor (HF) is a score function, which takes a final decision of selecting a best candidate network from a set of candidate networks. A candidate network, which has the highest value of "Handoff Factor (HF)" is selected as the best interface for handoff and all the current information of the current network are transported to new selected target network.

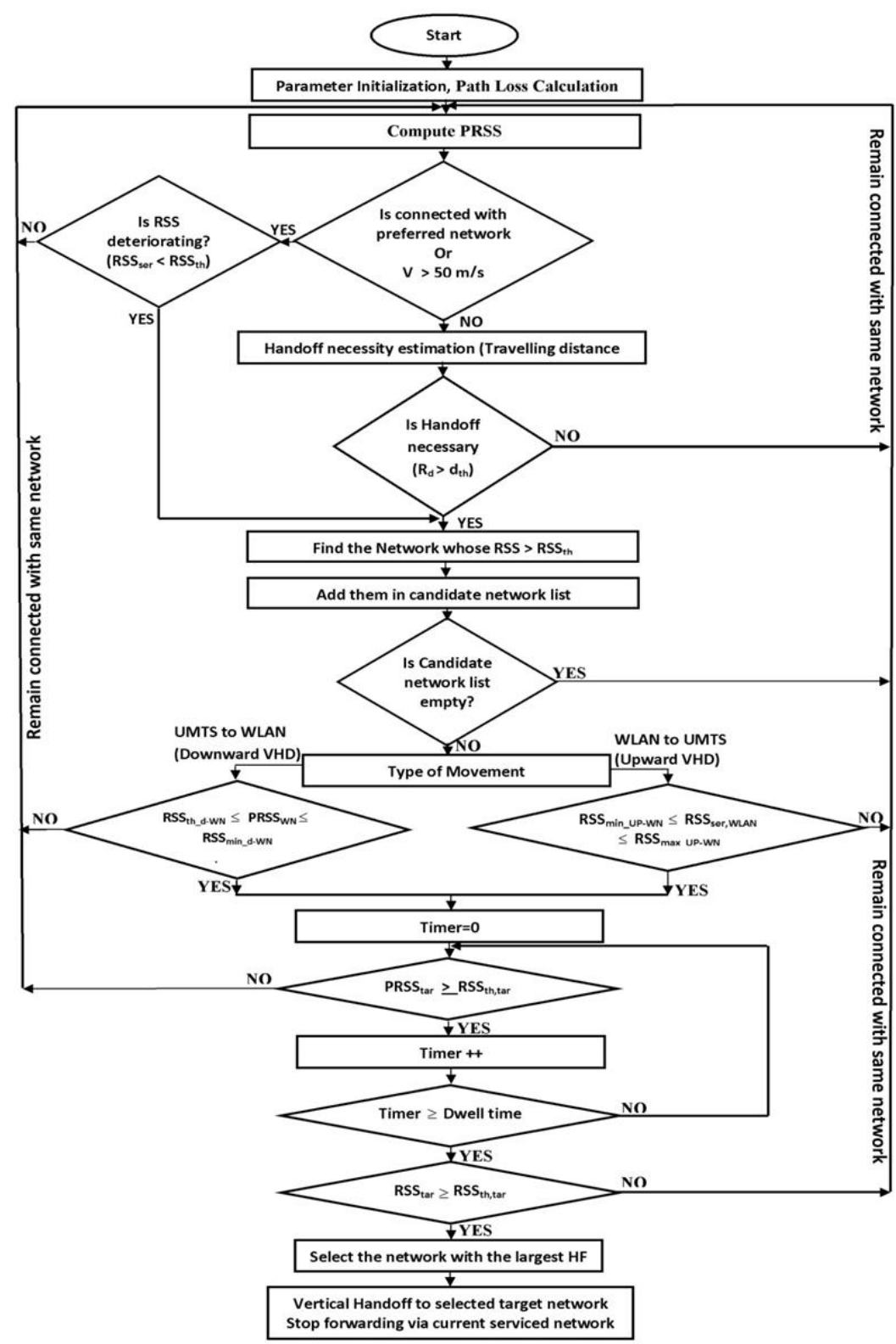

Figure 2. Flowchart of Target Network Selection \& Execution Module 


\section{SIMULATION SETUP}

MATLAB Version 7.12.0.535 (R2011a) is used to generate 1000 sets of random trajectory of a mobile node with random velocity from 1 to $50 \mathrm{~m} / \mathrm{s}$. In the simulation, an overlaid architecture of single UMTS, fourteen WLAN and three Wi-MAX are considered to cover an area of 3000*3000 m as shown in Figure 3. The transmission range of UMTS covers an area of $3000 \mathrm{~m}$, Wi-MAX covers an area of $1000 \mathrm{~m}$ and WLAN covers an area of $250 \mathrm{~m}$. The bandwidth of UMTS, WLAN and Wi-MAX are $384 \mathrm{~kb} / \mathrm{s}, 11 \mathrm{Mb} / \mathrm{s}$, and $15 \mathrm{Mb} / \mathrm{s}$, respectively. The number of mobile nodes ranges from 1 to 10 , and are configured to use interfaces UMTS, Wi-Fi, and Wi-MAX. The received signal strength is sampled at every 0.1 sec. The various simulation parameters and network parameters considered for simulation are defined in Table 1 and Table 2.

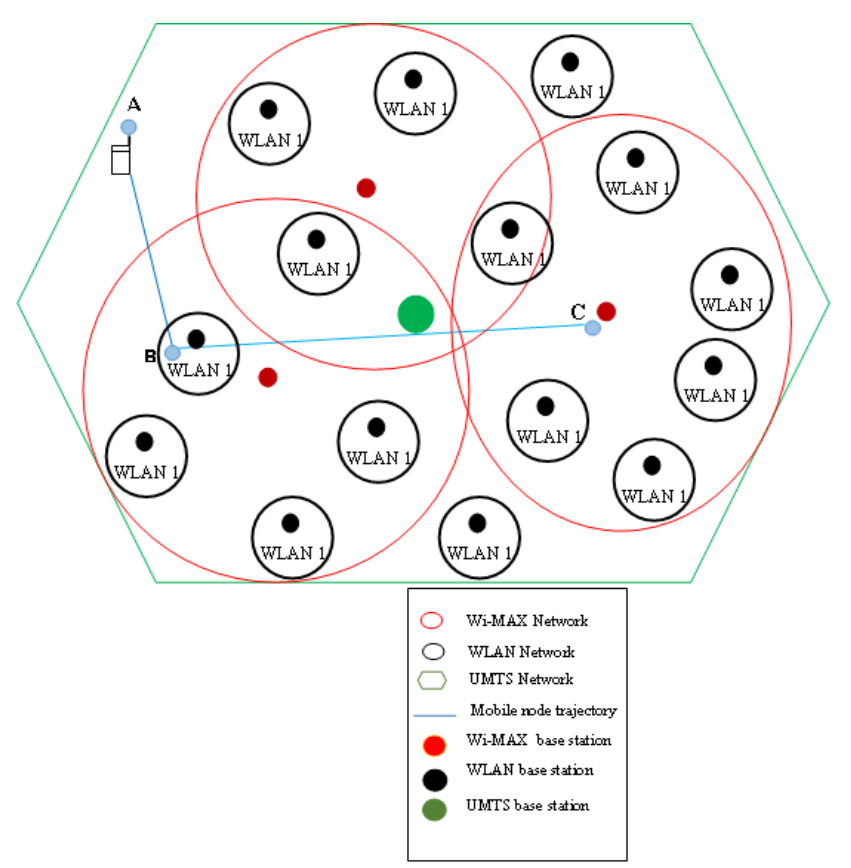

Figure 3. Overlaid Wireless Network of WLAN, Wi-MAX and UMTS

Table 1. Simulation parameters

\begin{tabular}{ccc}
\hline S. No. & Simulation Parameters & Values \\
\hline 1 & Topology Size (meter) & $3000 * 3000$ \\
2 & Number of mobile nodes & $1 \sim 10$ \\
3 & Number of WLANs & 14 \\
4 & Number of WMANs & 3 \\
5 & Number of UMTS & 1 \\
6 & Path loss constant, Z & 5 \\
7 & Path loss exponent, $\beta$ & 3.5 \\
\hline
\end{tabular}

Table 2. Network parameters

\begin{tabular}{|c|c|c|c|c|}
\hline S.No & Network parameters & WLAN & Wi-MAX & UMTS \\
\hline 1 & Bandwidth (min-max (Mbps)) & 1-Apr & 2-Jun & $0.1-0.3$ \\
\hline 2 & Cost (min-max) & $0.1-0.4$ & $0.3-0.5$ & $0.7-2.5$ \\
\hline 3 & User preference & 5 to 10 & 5 to 10 & 0 to 5 \\
\hline 4 & Mobile node velocity $(\mathrm{m} / \mathrm{s})$ & $<3$ & $<33$ & $<80$ \\
\hline 5 & Transmission range $(\mathrm{m})$ & 250 & 1000 & 3000 \\
\hline
\end{tabular}

\section{RESULTS AND ANALYSIS}

The proposed model triggers the handoff at an appropriate time depending upon the set of policies defined for WLAN and UMTS and selects an optimum target network at each point which has the highest value of Handoff Factor during its movement. Here, the simulated results are shown for three different random trajectories of mobile nodes.

Int J Rob \& Autom, Vol. 8, No. 1, March 2019 : 36 - 43 


\subsection{For mobile node movement from point $A$ to $B$}

Initially, when simulation starts mobile node is connected to UMTS network at point A. When mobile node moves from point A to point B as shown in Figure 4, it receives signal from the eight candidate networks Wi-MAX 2, Wi-MAX 3, WLAN 3, WLAN 4, WLAN 8, WLAN 12, WLAN 13, WLAN 14. Therefore, Handoff algorithm is triggered at this point due to distinct signal strength, bandwidth, cost, and user preference. Handoff factor is calculated at this point for all the eight eligible candidate networks. At this point, WLAN 4 is preferred network because of high handoff factor. Table 3 shows that, the presented model selects the target network from the candidate network during mobile node movement from point $\mathrm{A}$ to $\mathrm{B}$.

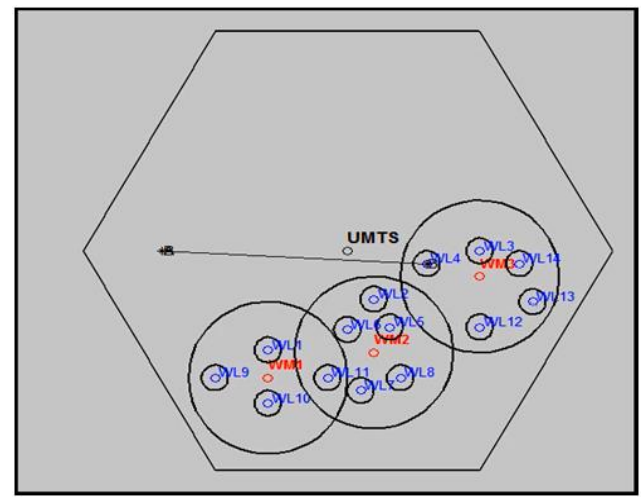

Figure 4. Mobile Node Movement from Point A to B

Table 3. Preferred Network (Mobile Node Movement from Point A to B)

\begin{tabular}{|c|c|c|c|c|c|c|c|}
\hline $\begin{array}{l}\text { Mobile Node } \\
\text { Location }\end{array}$ & WB & $\mathrm{WC}$ & WB & $\begin{array}{l}\text { Candidate } \\
\text { Network }\end{array}$ & Handoff factor & $\begin{array}{l}\text { Preferred } \\
\text { Network }\end{array}$ & $\begin{array}{l}\text { Distance which } \\
\text { Handoff Occur }\end{array}$ \\
\hline B & 0.0158 & 0.5105 & 0.3837 & $\begin{array}{c}\text { Wi-MAX } 2 \\
\text { Wi-MAX } 3 \\
\text { WLAN } 3 \\
\text { WLAN } 4 \\
\text { WLAN } 8 \\
\text { WLAN } 12 \\
\text { WLAN } 13 \\
\text { WLAN } 14\end{array}$ & $\begin{array}{c}0.01248 \\
0.27374 \\
0.99474 \\
1.508 \\
1.347 \\
1.4584 \\
0.94955 \\
1.4371\end{array}$ & WLAN 4 & 1000,50 \\
\hline
\end{tabular}

\subsection{For mobile node movement from $B$ to $C$}

As shown in Figure 5, when mobile node moves from point $\mathrm{B}$ to point $\mathrm{C}$. The mobile node receives signal from Wi-MAX 2, Wi-MAX 3, WLAN 3, WLAN 4, WLAN 8, and WLAN 12, At this point, Wi-MAX 2 is preferred network because of high handoff factor. Table 4 shows the candidate network and eligible network at point $\mathrm{C}$.

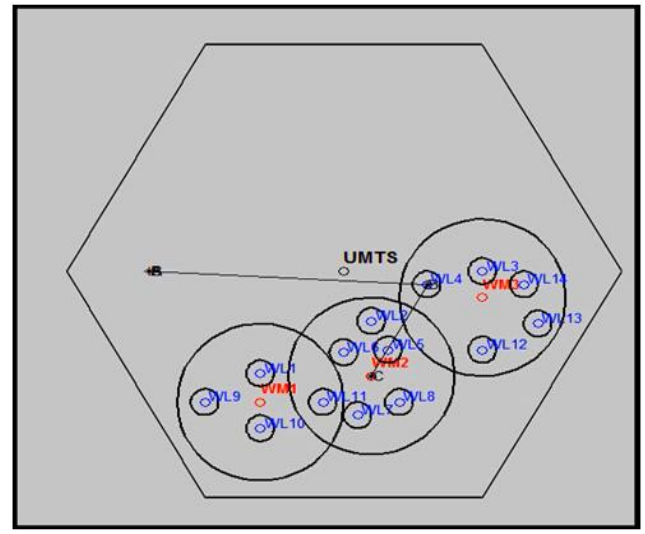

Figure 5. Mobile Node Movement from Point B to C 
Table 4. Preferred Network (Mobile Node Movement from Point B to C)

\begin{tabular}{|c|c|c|c|c|c|c|c|}
\hline $\begin{array}{l}\text { Mobile } \\
\text { Node } \\
\text { Location }\end{array}$ & WB & WC & WB & $\begin{array}{l}\text { Candidate } \\
\text { Network }\end{array}$ & $\begin{array}{l}\text { Handoff } \\
\text { factor }\end{array}$ & $\begin{array}{l}\text { Preferred } \\
\text { Network }\end{array}$ & $\begin{array}{l}\text { Distance which } \\
\text { Handoff Occur }\end{array}$ \\
\hline \multirow[t]{8}{*}{$\mathrm{C}$} & 0.02055 & 0.5785 & 0.3150 & Wi-MAX 2 & 1.8181 & Wi-MAX2 & 200.350 \\
\hline & & & & Wi-MAX 3 & 1.8081 & & \\
\hline & & & & WLAN 3 & 0.377 & & \\
\hline & & & & WLAN 4 & 1.0818 & & \\
\hline & & & & WLAN 8 & 0.58051 & & \\
\hline & & & & WLAN 12 & 0.45041 & & \\
\hline & & & & WLAN 13 & 0.84875 & & \\
\hline & & & & WLAN 14 & 0.08487 & & \\
\hline
\end{tabular}

\subsection{For mobile node movement from $C$ to $D$}

In Figure 6 is similarly, when a mobile node moves from point $C$ to point D. Handoff Factor of Wi-MAX 3 is high as compared to other eligible candidate networks. Therefore, Wi-MAX 3 is a preferable network at point $\mathrm{D}$ because of its high Handoff Factor as shown in Table 5.

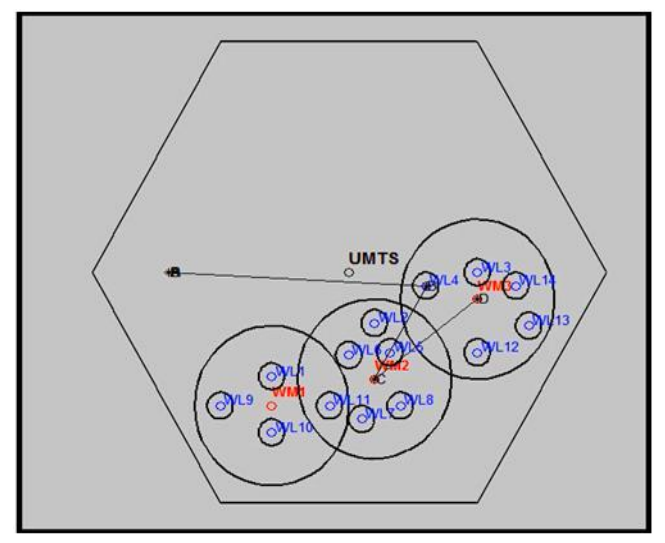

Figure 6. Mobile node movement from point $\mathrm{C}$ to $\mathrm{D}$

Table 5. Preferred network (Mobile node movement from point C to D)

\begin{tabular}{|c|c|c|c|c|c|c|c|}
\hline $\begin{array}{l}\text { Mobile Node } \\
\text { Location }\end{array}$ & WB & WC & WB & $\begin{array}{c}\text { Candidate } \\
\text { Network }\end{array}$ & $\begin{array}{l}\text { Handoff } \\
\text { factor }\end{array}$ & $\begin{array}{l}\text { Preferred } \\
\text { Network }\end{array}$ & $\begin{array}{l}\text { Distance which } \\
\text { Handoff Occur }\end{array}$ \\
\hline $\mathrm{D}$ & 0.0250 & 0.5047 & 0.3893 & $\begin{array}{c}\text { Wi-MAX } 2 \\
\text { Wi-MAX } 3 \\
\text { WLAN } 3 \\
\text { WLAN } 4 \\
\text { WLAN } 8 \\
\text { WLAN } 12 \\
\text { WLAN } 13 \\
\text { WLAN } 14\end{array}$ & $\begin{array}{c}1.4911 \\
1.5384 \\
1.123 \\
1.3181 \\
1.1951 \\
1.0983 \\
1.1345 \\
1.484\end{array}$ & Wi-MAX3 & 400.300 \\
\hline
\end{tabular}

\section{CONCLUSIONS}

In this chapter, a method to select an optimum target network is presented. This method is based on Weights Estimation and Handoff Factor Estimation algorithm. Weights of input decision parameters are calculated, and handoff factors of candidate networks are calculated using a cost function. The network with the highest handoff factor is selected as the handover target. This method is able to provide the always best connected services to users. Hence enhances user's satisfaction level comparing with methods that consistently choose one access network.

\section{REFERENCES}

[1] Gazis, V., Alonistioti, N. and Merakos, L., "Toward a generic always best connected capability in integrated WLAN/UMTS cellular mobile networks (and beyond)," IEEE Wireless Communications, vol. 12, no. 3, pp. 20-29, 2005.

Int J Rob \& Autom, Vol. 8, No. 1, March 2019: $36-43$ 
[2] Dutta, A., Das, S., Famolari, D., Ohba, Y., Taniuchi, K., Fajardo, V., and Schulzrinne, H., "Seamless proactive handover across heterogeneous access networks," Wireless Personal Communications, vol. 43, no. 3, pp. 837-855, 2007.

[3] Wang, H.J., Katz, R.H. and Giese, J., February. "Policy-enabled handoffs across heterogeneous wireless networks," In Second IEEE Workshop on Mobile Computing Systems and Applications (WMCSA'99), pp. 51-60, IEEE Proceedings, 1999.

[4] Zhu, F. and McNair, J., March. "Optimizations for vertical handoff decision algorithms," In Wireless communications and networking conference (WCNC), vol. 2, pp. 867-872, IEEE, 2004.

[5] Zhu, F. and McNair, J., "Multiservice vertical handoff decision algorithms," EURASIP Journal on wireless communications and networking, vol. 2, pp. 52-52, 2006.

[6] Lee, W., Kim, E., Kim, J., Lee, I. and Lee, C., "Movement-aware vertical handoff of WLAN and mobile WiMAX for seamless ubiquitous access," IEEE Transactions on Consumer Electronics, vol. 53, no. 4, 2007.

[7] He, D., Chi, C., Chan, S., Chen, C., Bu, J. and Yin, M., "A simple and robust vertical handoff algorithm for heterogeneous wireless mobile networks,” Wireless Personal Communications, vol. 59, no. 2, pp. 361-373, 2011.

[8] Kunarak, S. and Suleesathira, R. "Algorithmic vertical handoff decision and merit network selection across heterogeneous wireless networks," WSEAS Transactions on Communications, vol. 12, no. 1, pp.1-13, 2013.

[9] Xia, L., Ling-ge, J., Chen, H. and Hong-Wei, L., "An intelligent vertical handoff algorithm in heterogeneous wireless networks," In International Conference on Neural Networks and Signal Processing, pp. 550-555, IEEE, June, 2008.

[10] Nasser, N., Hasswa, A., \& Hassanein, H., "Handoffs in fourth generation heterogeneous networks," IEEE Communications Magazine, vol. 44, no. 10, pp. 95-103, 2006.

[11] Quality of service. UMTS. [Online]. Available: http://www.umtsworld.com/technology/qos.htm. 